\title{
Analisis Biaya Modal Terhadap Tingkat Pengembalian Investasi Pada PT. Mitra Adiprakasa, Tbk.
}

\author{
Intan Fitriyani', Aris Munandar ${ }^{2}$ \\ e-mail: ${ }^{1}$ Intanfitri16.stiebima@gmail.com, ${ }^{2}$ aris.stiebima@gmail.com \\ Sekolah Tinggi Ilmu Ekonomi (STIE) BIMA

\begin{tabular}{ccc}
\hline Diterima & Direvisi & Disetujui \\
$28-03-2020$ & $24-07-2020$ & $21-09-2020$ \\
\hline
\end{tabular}

\begin{abstract}
Abstrak - Biaya modal merupakan faktor utama dalam kegiatan operasional perusahaan, termasuk kegiatan investasi. Fenomena Investasi belakangin ini menjadi sangat trendi dan menarik setiap perusahaan/ investor untuk melakukan kegiatan investasi. Karena kagiatan investasi yang dilakukan menjanjikan hasil yang menggiurkan. Seperti yang diangkat penulis pada objek penelitian di PT. Mitra Adiprakasa, Tbk yang ingin menganalsis tingkat pengembalian investasinya atas biaya yang dikorbankan perusahaan, Tujuan dari penelitian ini adalah untuk mengetahui ada atau tidaknya pengaruh biaya modal terhadap tingkat pengembalian investasi pada PT. Mitra Adiprakasa, Tbk. Metode yang digunakan adalah berupa data kuantitatif. Populasi dalam penelitian ini yaitu mulai dari tahun 2004 sejak listing di (BEI) sampai tahun 2018, dengan sampel penelitian sebanyak 5 tahun dari tahun 2014-2018. Sample diambil secara purposive sampling dengan metode pengumpulan data berupa studi pustaka. Tehnik analisa data adalah regresi linear sederhana dengan menggunakan software IBM SPSS 20 sebagai alat tabulasi data. Data yang digunakan merupakan data sekunder yang didapat dari PT. Mitra Adiprakasa, Tbk. Hasil dari penelitian ini menunjukan bahwa tidak ada pengaruh yang signifikan antara biaya modal dengan tingkat pengembalian investasinya. Hal ini disebabkan oleh laporan keuaangan PT. Mitra Adiprakasa, Tbk pada periode 2014-2018 yang mengalami fluktuatif (Kenaikan dan penurunan).
\end{abstract}

Kata Kunci: Analisis, Biaya Modal, Tingkat Pengembalian Investasi

\begin{abstract}
The cost of capital is a major factor in the speed of a company's operations, including investment activity. The phenomenon of investment has become very trendy and attracts every investor company to make investment activities. Because the investment activities carried out promise lucrative results. As stated by the author on the object of research at PT Mitra Adiprakasa, Tbk, who wants to analyze the rate of return on investment at the costs sacrificed by the company, the purpose of this research is to find out whether there is or is not a change in the cost of capital to personnel. development of investment in PT Mitra Adiprakasa, Thk. The method used is in the form of quantitative data. The population in this study, which began in 2004 from Hsting in (BEI) to 2018, with a research sample of 5 years and 2014-2018 The sample was taken by purposive sampling with the data collection method in the form of a literature study. Tehruk analysis. The data is simple linear regen using IBM SPSS 20 software as a means of collecting data. The data used are secondary data obtained from PT Mitra Adiprakasa, Thk. The results and this research show that there is no significant difference between the capital age and the level of return of its uwest This is due to the financial report of PT Mtra Adiprakasa, Tbk in the 2014-2018 period which was volatile (increase and decrease).
\end{abstract}

Keywords : Analysis, Cost of capital, Return on investment

\section{PENDAHULUAN}

Secara umum modal mempunyai peranan yang cukup penting dalam aktivitas operasional perusahaan, tanpa adanya modal maka kegiatan operasional perusahaan akan terhambat termasuk kegiatan pendanaan investasi perusahaan. Biaya modal merupakan salah satu aspek penting dalam menganalisis kegiatan investasi karena biasanya digunakan sebagai alat ukur untuk menentukan diterima atau ditolaknya suatu usulan investasi.

Biaya modal merupakan point penting dalam menganalisis investasi karena dapat menunjukan tingkat minimum laba investasi yang harus diperoleh dari investasi tersebut. Jika investasi itu tidak dapat menghasilkan laba/ profit sekurang-kurangnya sebesar biaya yang dikeluarkan maka investasi 
tersebut tidak perlu dilakukan karena dianggap tidak menguntungkan bagi perusahaan.

"Biaya yaitu harga perolehan yang dikorbankan atau digunakan dalam rangka memperoleh (revenues) dan akan dipakai sebagai pengurangan pendapatan". (Supriyono, 2011)

Menurut Atmaja "Modal merupakan dana yang digunakan untuk membiayai pengadaan aktiva dan operasional perusahaan. Modal terdiri dari item-item yang ada disisi kanan suatu neraca, yaitu: hutang, saham biasa, saham preferen dan laba ditahan". (Atmaja, 2002)

"Biaya modal adalah biaya yang harus dikeluarkan atau dibayarkan oleh perusahaan untuk mendapatkan modal yang digunakan untuk investasi perusahaan, dan biaya modal juga adalah penjumlahan rata-rata tertimbang dari biaya hutang, biaya preferred stock dan biaya modal sendiri”. Biaya modal penting dalam pembelanjaan perusahaan, karena dapat dipakai untuk menentukan besarnya biaya yang secara riil harus ditanggung oleh perusahaan untuk memperoleh modal dari berbagai sumber. (Munawir, 2011)

Sedangkan investasi yang dilakukan oleh para investor/ perusahaan dalam bentuk saham ialah untun memperoleh keuntungan yang berupa deviden atau capital gain yang tinggi. Untuk itu investor perlu menganalilis perusahaan yang akan dibeli sahamnya. Informasi laporan keuangan yang dikeluarkan oleh perusahaan adalah salah satu informasi yang mudah didapatkan dibanding informasi lainnya. selain itu informasi laporan keuangan akuntansi sudah cukup menggambarkan perkembangan kondisi perusahaan.

"Investasi merupakan penundaan konsumsi sekarang untuk digunakan didalam produksi yang efisiensi selama periode waktu yang tertentu". (Jogiyanto, 2003)

"Investasi adalah komitmen atas sejumlah dana atau sumber daya lainnya yang dilakukan pada saat ini, dengan tujuan memperoleh keuntungan dimasa datang”. (Tandelilin, 2010)

PT. Mitra Adiprakasa, Tbk sebagai objek dalam penelitian ini merupakan perusahaan retail gaya hidup terkemuka serta mengelola beberapa merk perusahaan ternama di Indonesia dan sudah terdaftar di Bursa Efek Indonesia.

Tabel 1. Biaya Modal Dan Tingkat Pengembalian Investasi pada PT. Mitra Adiprakasa, Tbk. 5 tahun terakhir (2014-2018)

\begin{tabular}{|c|c|c|}
\hline Tahun & $\begin{array}{c}\text { Biaya } \\
\text { Modal } \\
(\mathrm{Rp})\end{array}$ & $\begin{array}{c}\text { Tingkat Pengembalian } \\
\text { Investasi (Rp) }\end{array}$ \\
\hline 2014 & 25,64 & 124,01 \\
\hline 2015 & 25,47 & 67,34 \\
\hline
\end{tabular}

\begin{tabular}{|l|l|l|}
\hline 2016 & 28,10 & 71,79 \\
\hline 2017 & 28,43 & 75,32 \\
\hline 2018 & 28,12 & 53,71 \\
\hline
\end{tabular}

Sumber: Data sekunder, diolah 2019

Tabel diatas menunjukan gambaran mengenai laporan keuangan PT. Mitra Adiprakasa, Tbk. Periode 2014-2018. Dari segi biaya modal (Hasilnya sudah di LN kan/ Logaritma Natural agar nilainya sebanding dengan tingkat pengembalian investasi), mengalami fluktuatif (Naik turun) dimana pada tahun 2015 mengalami penurunan, walaupun penurunannya sangat tipis hal ini disebabkan karena biaya laba ditahan yang mengalami penurunan. Sedangkan pada tahun 2018 kembali mengalami penurunan walaupan sangat tipis hal ini disebabkan karena biaya hutang sebelum pajak yang mengalami kenaikan.

Dari segi tingkat pengembalian investasi mengalami penurunan hal ini disebabkan oleh total penjualan yang semakin tinggi sedangkan investasi yang semakin tinggi sehingga tidak sebanding dengan tingkat pengembalian investasinya.

Berdasarkan uraian tersebut maka dapat ditarik rumusan masalah sebagai berikut : Apakah terdapat pengaruh yang signifikan biaya modal terhadap tingkat pengembalian investasi pada PT. Mitra Adiprakasa, Tbk. ?

Tujuan dari penelitian untuk mengetahui dan menganalisis adakah pengaruh yang signifikan biaya modal terhadap tingkat pengembalian investasi pada PT. Mitra Adiprakasa, Tbk. ?

\section{Tinjauan Pustaka \\ 1. Biaya Modal}

"Biaya modal merupakan semua biaya rill dikeluarakan oleh perusahaan dalam rangka mendapatkan sumber dana yang digunakan untuk investasi perusahaan”. (Sutrisno, 2011)

"Menyatakan bahwa indikator yang digunakan untuk mengukur variabel biaya modal yaitu dengan menghitung biaya modal rata-rata tertimbang (Weighted average cost of capital atau WACC) dapat dihitung dengan rumus": (Made Sudana, 2013)

$$
\text { WACC }=\text { Wd.Kd }(1-T)+\text { Wp. Kp (Ks atau Ke) }
$$

\section{Dimana :}

$\begin{array}{ll}\mathrm{WACC} & =\text { Biaya rata-rata tertimbang } \\ \mathrm{Wd} & =\text { Persentase hutang dari modal } \\ \mathrm{Wp} & =\text { Persentase saham preferen dari } \\ \text { modal } & =\text { Persentase saham biasa atau laba } \\ \mathrm{Ws} & \end{array}$
ditahan dari modal
$\mathrm{Kd}$
$\mathrm{Kp}$
= Biaya hutang
= Biaya saham preferen
Ks $\quad=$ Cost Of Equity 
$\mathrm{Ke}$

$\mathrm{T}$

$$
\text { = Biaya saham biasa baru }
$$$$
=\text { Pajak (Dalam persentase) }
$$

Komponen dari rumus WACC:

a. "Biaya modal rata-rata tertimbang merupakan komponen dari biaya bunga, hutang, saham biasa, ekuitas". Dimana untuk memperoleh nilai Wd dan Ws adalah sebagai berikut : (Brigham Dan Huston, 2009)

$$
\begin{gathered}
\mathrm{Wd}=\frac{\text { Total Hutang }}{\text { Total Aktiva }} \\
\mathrm{Ws}=\frac{\text { Total Modal }}{\text { Total Aktiva }}
\end{gathered}
$$

b. Untuk menentukan besarnya biaya hutang sebelum pajak maka bisa dilakukan dengan cara menghitung besarnya tingkat hasil internal (Yield to maturity) atas arus kas obligasi yang dinotasikan dengan $\mathrm{Kd}$. "Perhitungan biaya hutang digunakan untuk menemukan suku bunga (Rate) terbaik bagi perusahaan melakukan pinjaman modal dalam mendanai kegiatannya". (Mardiyanto, 2009)

$$
\mathrm{Kd}=\frac{\text { Total Hutang }}{\text { Hutang Jangka Panjang }} \times 100 \%
$$

c. Biaya modal sendiri dapat dihitung dengan dengan menggunakan rumus sebagai berikut :

$$
\mathrm{Ks}=\frac{\text { EAT }(\text { Earning After Tax })}{\text { Modal Sendiri }}
$$

d. Biaya saham preferen

$$
\mathrm{Kp}=\frac{\mathrm{Dp}}{\mathrm{Pn}}
$$

Keterangan :

$\mathrm{Kp}=$ Biaya saham preferen

$\mathrm{Dp}=$ Deviden saham preferen

$\mathrm{Pn}=$ Harga saham preferen bersih yang diterima

\section{Tingkat Pengembalian Investasi}

"Tingkat pengembalian investasi dapat menunjukkan kemampuan perusahaan dalam memperoleh laba dari aktiva yang digunakan. (Agus Sartono, 2001)

"ROI (Return On Investment) merupakan salah satu bentuk dari rasio profitabilitas yang dimaksudkan dapat mengukur kemampuan perusahaan dengan keseluruhan dana yang ditanamkan dalam aktiva yang digunakan untuk operasional perusahaan untuk menghasilkan keuntungan”. (Munawir, 2010)
Menyatakan "ROI sering disebut return on total asset dipergunakan untuk mengukur kemampuan perusahaan dalam menghasilkan keuntungan dengan menggunakan keseluruhan aktiva yang dimilikinya". Dapat diukur dengan rumus : (Abdullah Faisal, 2002)

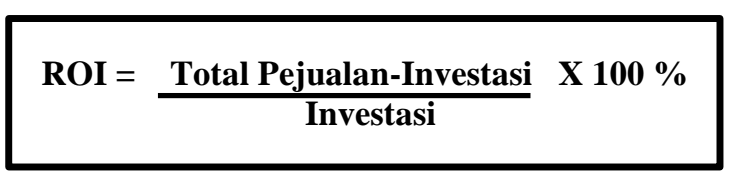

\section{METODE PENELITIAN}

Menurut Sugiyono, (2012:11) : "Metode penelitian asosiatif adalah yang bertujuan untuk mengetahui pengaruh atau hubungan antara dua variabel atau lebih". (Sugiyono, 2012)

Jenis penelitian dalam penelitian ini ialah penelitian asosiatif. Penelitian asosiatif merupakan suatu jenis penelitian dengan tujuan untuk mengetahui pengaruh ataupun juga hubungan antara dua variabel atau lebih serta hubungan sebab akibatnya.

Tujuan dari penelitian ini adalah untuk mencari pengaruh antara biaya modal (X) sebagai variabel bebas dengan tingkat pengembalian investasi (Y) sebagai variabel terikat.

Menurut Burhan Bungin, (2009:122) : "Data sekunder adalah data yang diperoleh dari sumber kedua atau sumber sekunder dari data yang kita butuhkan.”. (Burhan Bungin, 2009)

Penelitian ini menggunakan pendekatan kuantitatif. Data utama yang diperlukan adalah data sekunder yang berasal dari laporan keuangan dalam kurun waktu 5 tahun terakhir yaitu dari tahun 2014-2018 yang diperoleh dari PT. Mitra Adiprakasa, Tbk.

Menurut Sugiyono, (2013:49) : "Populasi adalah wilayah generalisasi yang terdiri atas objek/subjek yang mempunyai kuantitas dan karakter tertentu yang yang ditetapkan oleh penelitinuntuk dipelajari dan kemudian ditarik kesimpulannya". (Sugiyono, 2013) Sugiyono, (2011:81) : "sample adalah bagian dari jumlah dan kaakteristik yang dimiliki oleh popolasi tersebut". (Sugiyono, 2011)

Adapun populasi yang digunakan dalam penelitian ini yaitu mulai dari tahun 2004 semenjak listing di BEI (Bursa Efek Indonesia) samapi tahun 2018.

Sample dalam penelitian ini yaitu selama 5 tahun terakhir mulai dari tahun 2014-2018.

Menurut Sugiyono, (2010) : "Purposive sampling adalah tehnik untuk menentukan sample penelitian dengan beberapa pertimbangan tertentu yang bertujuan agar data yang diperoleh nantinya representatif'. (Sugiyono, 2010)

Tehnik pengambilan sample dalam penelitian ini adalah purposive sampling. Adapun pertimbangan 
yang dilakukan penulis adalah mengenai ketersediaan data serta menggunakan data terbaru yang sudah diaudit.

Menurut Sugiyono, (2009) : "Definisi instrumen penelitian adalah alat-alat bantu yang digunakan oleh peneliti dalam mengukur fenomena alam serta sosial yang sesuai dengan variabel penelitian". (Sugiyono, 2009)

Instrumen dalam penelitian ini ialah berupa daftar table yang terdiri atas data laporan total hutang, total aktiva, total modal, hutang jangka panjang, laba setelah pajak, deviden saham preferen, harga saham preferen, dan pajak. (Sesuai dengan kmponen rumus WACC/ Biaya modal) Kemudian data total penjualan dan investasi (Sesuai dengan komponen rumus ROI/ Tingkat pengembalian investasi) selama 5 tahun terakhir.

Tehnik pengumpulan data yang digunakan yaitu studi pustaka. Lokasi dan tempat penelitian ini dilakukan pada PT. Mitra Adiprakasa, Tbk. yang didirikan pada tanggal 23 januari 1995, dan kantor pusatnya terletak di Sahid Sudirman Center, Lt. 29, Jl. Jendral Sudirman kav. 86, Jakarta 10220-Indonesia.

Penelitian ini menggunakan tehnik analisis data regresi linear sederhana, koefisien korelasi sederhana, koefisien determinasi sederhana, dan uji t.

Tehnik analisis data adalah sebagai berikut :

a. Analisis regresi linier sederhana

Sugiyono, (2017:261) menyatakan bahwa :'Regresi linier sederhana didasarkan pada hubungan fungsional ataupun kausal satu variable independen dengan satu variabl dependen”. (Sugiyono, 2017)

Kegunaan analisis regresi linier sederhana menurut Somantri, (2011:243) : "Regresi linier sederhana digunakan untuk mempelajari hubungan linier antara dua variabel". (Somantri, 2011)

$$
\mathrm{Y}=\mathrm{a}+\mathrm{bX}
$$

$\mathrm{Y}=$ variabel terikat

$\mathrm{X}=$ variabel bebas

$\mathrm{a}=$ konstanta

$\mathrm{b}=$ koefisien variabel

Persamaan umum regresi linier sederhana adalah: Dimana nilai a dan b dicari terlebih dahulu dengan menggunakan persamaan sebagai berikut :

$$
\begin{gathered}
\mathrm{a}=\frac{\left(\sum X^{2}\right)\left(\sum Y\right)-\left(\sum X\right)\left(\sum X Y\right)}{n \sum X^{2}-\left(\sum X\right)^{2}} \\
\mathrm{~b}=\frac{n \sum X Y-\left(\sum X\right)\left(\sum X Y\right)}{n \sum X 2-\left(\sum X\right) 2}
\end{gathered}
$$

b. Koefisien korelasi sederhana

Koefisien korelasi sederhana digunakan untuk menganalisis kekuatan hubungan atau nilai korelasi kedua variabel dimana variabel lainnya dianggap berpengaruh dikendalikan atau dibuat tetap (variabel control).

$$
r=\frac{n \sum X Y-\left(\sum X\right)\left(\sum Y\right)}{\sqrt{\left\{n \sum X^{2}-\left(\sum X\right)^{2}\right\}}-\left\{n \sum Y^{2}-\left(\sum Y\right)^{2}\right\}}
$$

Tabel 2. Nilai korelasi dan Tingkat Hubungan

\begin{tabular}{|c|c|c|}
\hline No. & Nilai Korelasi & Tingkat Hubungan \\
\hline 1 & $0,00-0,199$ & Sangat Lemah \\
\hline 2 & $0,20-0,399$ & Lemah \\
\hline 3 & $0,40-0.599$ & Cukup \\
\hline $1 / 4$ & $0,60-0,799$ & Kuat \\
\hline 5 & $0,80-0,100$ & Sangat Kuat \\
\hline
\end{tabular}

Sumber : Sugiyono $(2014: 250)$

c. Koefisien determinasi sederhana

Menurut Sugiyono, (2015 : 263) : "Dalam analisis korelasi terdapat suatu angka yang disebut dengan koefisien determinasi yang sering disebut koefisien penentu, karena besarnya adalah kuadrat dari koefisien korelasi (r). Sehingga koefisien ini berguna untuk mengetahui besarnya kontribusi pengaruh biaya modal terhadap tingkat pengembalian investasi pada PT. Mitra Adiprakasa, Tbk. dengan menggunakan rumus sebagai berikut": (Sugiyono, 2015)

$$
\mathrm{KD}=\left(\mathrm{r}^{2}\right) \times 100 \%
$$

\section{d. Uji t}

Menurut Ghozali, (2013:98) : “Uji t digunakan untuk menguji hipotesis secara parsial guna menunjukan pengaruh tiap variabel independen secara individu terhadap variabel dependen". (Ghozali, 2013)

Uji $\mathrm{t}$ adalah pengujian koefisien regresi masingmasing variabel independen terhadap variabel dependen, untuk mengetahui seberapa besar pengaruh variabel independen terhadap variabel dependen. Dengan menggunakan rumus :

$$
t=\frac{r \sqrt{n-2}}{\sqrt{1-r^{2}}}
$$

\section{HASIL DAN PEMBAHASAN}

\section{Gambar 1. Regresi Linear Sederhana}

Coefficients

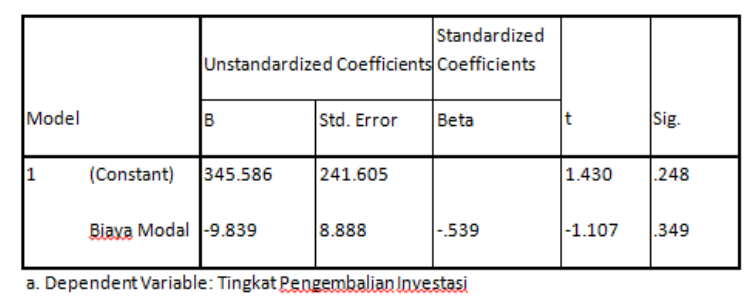

Sumber : SPSS 
Berdasarkan output SPSS pada tabel 2.1 maka diperoleh persamaan regresi linear sederhana sbb : $\mathrm{Y}=345,586+(-9,839) \mathrm{X}$

Konstanta $=\mathrm{a}=345,586$ artinya jika biaya modal $=0$ maka tingkat pengembalian investasi $=345,586$

Koefisien variabel $=-9,839$, artinya jika biaya modal naik $1 \%$ maka tingkat pengembalian investasi akan naik sebesar $-9,839$

Gambar 2. Koefisien Korelasi Sederhana

\begin{tabular}{|c|c|c|c|}
\hline \multicolumn{4}{|c|}{ Correlations } \\
\hline & & Bigya Modal & $\begin{array}{c}\text { Tingkat } \\
\text { Reogembalian } \\
\text { Investasi }\end{array}$ \\
\hline Bigys Modsl & $\begin{array}{l}\text { Pearson Correlation } \\
\text { Sig. (2-tailed) } \\
\mathrm{N}\end{array}$ & 5 & $\begin{array}{r}.539 \\
.349 \\
5 \\
\end{array}$ \\
\hline $\begin{array}{l}\text { Tingkat Pengembalian } \\
\text { loxestasi. }\end{array}$ & $\begin{array}{l}\text { Pegrson Correlation } \\
\text { Sig. (2-tailed) } \\
\text { N }\end{array}$ & $\begin{array}{r}.539 \\
.349 \\
5\end{array}$ & $\begin{array}{l}1 \\
5\end{array}$ \\
\hline
\end{tabular}

Sumber : SPSS

Berdasarkan output SPSS pada tabel diatas, maka diperoleh nilai korelasi sebesar $(-0,539)$ yang berarti bahwa tingkat keeratan hubungan antara Biaya modal terhadap Tingkat pengembalian investasi berada pada tingkat yang sangat lemah (minus).

\section{Gambar 3. Koefisien Determinasi Sederhana}

\begin{tabular}{|l|r|r|r|c|}
\hline & & & \multicolumn{1}{|c|}{ Model Summary } \\
Model & $R$ & R Square & \multicolumn{1}{c|}{$\begin{array}{c}\text { Square } \\
\text { Squar }\end{array}$} & $\begin{array}{c}\text { Std. Error of the } \\
\text { Estimate }\end{array}$ \\
\hline 1 & $.539^{2}$ & .290 & .053 & 26.04057 \\
\hline
\end{tabular}

๑. Predictors: (Constant), Bigya Modal

Sumber : SPSS

Berdasarkan output SPSS pada tabel diatas, maka diperoleh nilai Koefisien Determinasi $\left(\mathrm{R}^{2}\right)$ sebesar 0.290 atau $29 \%$ artinya kontribusi biaya modal terhadap tingkat pengembalian investasi yaitu sebesar $29 \%$ sedangkan sisanya $71 \%$ dipengaruhi oleh faktorfaktor lain yang tidak diteliti di penelitian ini.

\section{Coefficients}

$$
\text { Gambar 4. Uji Parsial (Uji t) }
$$

\begin{tabular}{|c|c|c|c|c|c|c|}
\hline \multirow{2}{*}{\multicolumn{2}{|c|}{ Model }} & \multicolumn{2}{|c|}{ Unstandardized Coefficients } & \multirow{2}{*}{\begin{tabular}{|l} 
Standardized \\
Coefficients
\end{tabular}} & \multirow[b]{2}{*}{$t$} & \multirow[b]{2}{*}{ Sig. } \\
\hline & & $B$ & Std. Error & & & \\
\hline 1 & (Constant) & 345.586 & 241.605 & & 1.430 & .248 \\
\hline & Biaxa Modal & -9.839 & 8.888 & -.539 & -1.107 & .349 \\
\hline
\end{tabular}

Sumber : SPSS
Berdasarkan output SPSS pada tabel diatas, maka diperoleh nilai $t$ hitung sebesar $(-0,539)$ dan tingkat signifikan sebesar 0, 349 Kemudian dibandingkan dengan t-tabel, dengan melakukan pengujian dua arah pada $\boldsymbol{\alpha} / 2=0,05 / 2=0,025$ dan derajat kebebasan $(\mathrm{dk})$ $=\mathrm{n}-\mathrm{k}=5-2=3$. Sehingga diperoleh nilai $\mathrm{t}$-tabel sebesar 3,1824.

\section{KESIMPULAN}

Kesimpulan dari hasil penelitian ini bahwa pengujian yang sudah dilakukan antar variabel adalah tidak ada pengaruh yang signifikan antara biaya modal (X) terhadap tingkat pengembalian investasi (Y).

Adapun saran dari penulis untuk penelititan selanjutnya baik untuk pihak perusahaan maupun peneliti berikutnya ialah untuk pihak perusahaan dalam menggunakan modal harus lebih efisien lagi, karena segala biaya yang dikeluarkan akan mempengaruhi perolehan laba/keuntungan perusahaan. Sedangkan untuk pihak peneliti berikutnya agar dapat menambah variabel penelitian, menambah sample penelitian, maupun mengambil data yang terupdate, untuk mempertajam keakuratan hasil penelitian.

\section{REFERENSI}

Abdullah Faisal. (2002). Dasar-Dasar Manajemen Keuangan UMM Press, Yogyakarta.

Agus Sartono. (2001). Manajemen Keuangan Teori Dan Aplikasi Edisi Keempat. Yogyakarta BEF.

Atmaja. (2002). Manajemen Keuangan. Yogyakarta : Andi.

Brigham Dan Huston. (2009). Dasar-Dasar Manajemen Keuangan, Buku Satu, Edisi Kesepuluh, Alih Bahasa Ali Akbar Yulianto. Jakarta : Selemba Empat.

Burhan Bungin. (2009). Penelitian Kualitatif. Cetakan Ketiga. Jakarta : Kencana Prenada Media Group.

Firdaus, Y. D. M., Amin, M., \& Junaidi. (2018). EJRA Vol. 08 No. 10 Agustus 2019 Fakultas Ekonomi dan Bisnis Universitas Islam Malang. E-Jra, 07(10), 119-131.

Ghozali. (2013). Aplikasi Analisis Multivariat dengan Program IBM SPSS. Edisi 7. Semarang: Penerbit Universitas Diponegoro.

Jogiyanto. (2003). Teori Portofolio Dan Analisis Investasi. Edisi Ketiga, BPFE. Yogyakarta. 
Made Sudana. (2013). Manajemen Keuangan Perusahaan Teori Dan Praktik. Jakarta : Erlangga.

Munawir. (2010). Analisis Laporan Keuangan Edisis Keempat. Cetakan Kelima Belas. Yogyakarta : Liberty

Munawir. (2011). Analisis Laporan Keuangan. Edisi Kesebelas. Yogyakarta : Liberty

Mardiyanto. (2009). Intisari Manajemen Keuangan. Jakarta : PT. Gramedia Widiasarana Indonesia (GRASINDO).

Rahma, S. (2014). Analisis Penetapan Struktur Moal Yang Optimal Guna Meningkatkan Nilai Perusahaan (Studi Pada PT. Seemount Garden Sejahtera, Jiwan, Kabupaten Madiun Periode 2011-2013). Jurnal Administrasi Bisnis S1 Universitas Brawijaya, 13(1), 83932.

Somantri. (2011). Dasar-Dasar Metode Statistika Untuk Penelitian , Bandung : Pustaka Setia.

Sugiyono. (2009). Metode Penelitian Kuantitatif Kualitatif dan R\&D, Bandung : Alfabet.

Sugiyono. (2010). Statistika Untuk Penelitian. Bandung : Alfabeta.

Sugiyono. (2011). Metode Penelitian Kuantitatif Kualitatif dan R\&D, Bandung : Alfabeta.
Sugiyono. (2012). Statistika Untuk Penelitian. Bandung : Alfabeta.

Sugiyono. (2013). Statistika Untuk Penelitian. Bandung : Alfabeta.

Sugiyono. (2015). Metode Penelitian Kuantitatif dan Kualitatif \& RND. Bandung: Alfabeta.

Sugiyono. (2017). Metode Penelitian Kuantitatif dan Kualitatif \& RND. Bandung: Alfabeta.

Supriyono. (2011). Akuntansi Biaya, Pengumpulan Biaya Dan Penentuan Harga Pokok, Buku 1 Edisi 2. Yogyakarta : BPFE.

Sutrisno. (2011). Manajemen Sumber Daya Manusia. Penerbit : Jakarta, Kencana.

Tandelilin. (2010). Portofolio Dan Investasi : Teori Dan Aplikasi . Edisi Pertama, Penerbit Kanisius (Anggota IKAPI). Yogyakarta.

Wangsawinangun, R. (2014). Penetapan Struktur Modal Yang Optimal Dalam Upaya Meningkatkan Nilai Perusahaan (Studi Pada PT. Astra International, Tbk dan Anak Perusahaan Tahun 2008-2012). Jurnal Administrasi Bisnis S1 Universitas Brawijaya, 9(2), 81713. 